\title{
7p22.1 microduplication syndrome
}

INSERM

\section{Source}

INSERM. (1999). Orphanet: an online rare disease and orphan drug data base. $7 p 22.1$ microduplication syndrome. ORPHA:314034

7p22.1 microduplication syndrome is a rare chromosomal anomaly syndrome, resulting from a partial interstitial microduplication of the short arm of chromosome 7 , characterized by intellectual disability, psychomotor and speech delays, craniofacial dysmorphism (including macrocephaly, frontal bossing, hypertelorism, abnormally slanted palpebral fissures, anteverted nares, low-set ears, microretrognathia) and cryptorchidia. Cardiac (e.g., patent foramen ovale and atrial septal defect), as well as renal, skeletal and ocular abnormalities may also be associated. 